\title{
Angiotensin-Converting Enzyme Gene Insertion/Deletion Polymorphism and Small Vessel Cerebral Stroke in Indian Population
}

\author{
Puttachandra Prabhakar, ${ }^{1}$ Tanima De, ${ }^{1}$ Dindagur Nagaraja, ${ }^{2}$ and Rita Christopher ${ }^{1}$ \\ ${ }^{1}$ Department of Neurochemistry, National Institute of Mental Health and Neuro Sciences, Bangalore 560029, India \\ ${ }^{2}$ Department of Neurology, National Institute of Mental Health and Neuro Sciences, Bangalore 560029, India \\ Correspondence should be addressed to Rita Christopher; rita.nimhans@yahoo.com
}

Received 20 July 2013; Revised 6 October 2013; Accepted 13 October 2013; Published 12 January 2014

Academic Editor: Robert M. Schainfeld

Copyright (c) 2014 Puttachandra Prabhakar et al. This is an open access article distributed under the Creative Commons Attribution License, which permits unrestricted use, distribution, and reproduction in any medium, provided the original work is properly cited.

Background. Hypertension is an established risk factor for small-vessel cerebral stroke and the renin-angiotensin system plays an important role in the maintenance of blood pressure. We aimed at evaluating the contribution of the angiotensin-converting enzyme ( $A C E$ ) gene insertion/deletion (I/D) polymorphism to the risk of small-vessel stroke in south Indian population. Materials and Methods. We investigated 128 patients diagnosed with small-vessel stroke and 236 age, and gender-matched healthy controls. ACE I/D polymorphism was detected by polymerase chain reaction. Results. Hypertension was significantly more prevalent in the patient group and was associated with 6-fold increase in risk for stroke. ACE genotypes were in Hardy-Weinberg equilibrium in both patients and controls. Prevalence of DD, ID, and II genotypes in cases (34.4\%, 43.7\%, and 28\%) did not differ significantly from controls (31.8\%, 43.2\%, and 25\%). The polymorphism was not associated with small-vessel stroke (OR: 1.34; 95\% CI: 0.52-1.55). However, diastolic blood pressure was associated with the ACE I/D genotypes in the patients. (DD; $90.2 \pm 14.2>$ ID; $86.2 \pm 11.9>$ II; $82.3 \pm 7.8 \mathrm{~mm} \mathrm{Hg}, P=0.047)$. Conclusion. Our study showed that hypertension, but not ACE I/D polymorphism, increased the risk of small-vessel stroke.

\section{Introduction}

Brain infarction due to ischemia in the perforating arteries which supply the brain white and deep grey matter nuclei, also known as lacunar infarction or lacunar stroke, accounts for $20 \%$ to $25 \%$ of all ischemic strokes [1]. Lacunar infarct forms part of the spectrum of cerebral small-vessel disease (SVD) which affects the brain diffusely and is the commonest vascular cause of cognitive impairment [2]. The prevalence rate of stroke in India varies across regions. While the prevalence is 5.4 per 1000 persons in the eastern part of India [3], southern India has reported a prevalence of 1.36 per 1000 persons [4]. The Indian Collaborative Acute Stroke Study (ICASS), a recent multicenter study conducted among 2162 admitted stroke patients across India, observed ischemic stroke in $77 \%$, hemorrhagic stroke in $22 \%$, and unspecified stroke in $1 \%$ of cases [5]. Data from a hospital-based stroke registry from south India shows that, of all ischemic stroke patients, $41 \%, 18 \%, 10 \%, 4 \%$, and $27 \%$ were classified as large-artery atherosclerosis, lacunae, cardioembolism, other determined etiology, and undetermined etiology, respectively [6]. Hypertension, diabetes, and smoking were the common risk factors among all the subtypes [7], similar to other populations. Hypertension is considered the foremost risk factor for lacunar stroke [8]. Several lines of evidence from family and twin studies support the hypothesis that genetic factors may contribute to the pathogenesis of SVD and lacunar stroke [9].

The gene encoding angiotensin-converting enzyme $(A C E)$, which converts angiotensin I to the vasoconstrictor angiotensin II and inactivates the vasodilator bradykinin, is considered to be an important candidate in cerebral SVD because of its role in blood pressure regulation, regulation of vascular endothelial function, and smooth muscle proliferation and tone [10]. The I/D polymorphism in intron 16 of $A C E$ is one of the most frequently studied genetic 
variations across different populations for association with vascular diseases. Despite being an intronic variation, it accounts for approximately half of the observed variance in plasma levels of the ACE protein [10]. Previous studies on $A C E \mathrm{I} / \mathrm{D}$ polymorphisms in lacunar strokes and other cardiovascular phenotypes have yielded conflicting results. The ACE D allele has been reported to be significantly associated with lacunar stroke in a few studies [8]. Few studies from western population have found no association $[11,12]$. Since the role of $A C E \mathrm{I} / \mathrm{D}$ polymorphisms in the pathogenesis of ischemic stroke due to cerebral SVD is controversial, our aim was to evaluate the association of this polymorphism with small-vessel stroke in south Indian population.

\section{Materials and Methods}

The study group comprised of 128 first-ever stroke patients, aged between 40 and 65 years, seen at either the emergency department or the neurology outpatient services, within a week after the onset of symptoms of the classic lacunar syndromes (pure motor hemiparesis, pure sensory stroke, sensorimotor stroke, ataxic hemiparesis, and dysarthria-clumsy hand syndrome), and diagnosed with stroke classed as "smallvessel” by the Trial of ORG 10172 in Acute Stroke Treatment (TOAST) classification [13]. Small-vessel occlusion or lacunar infarct was defined as an acute classic lacunar syndrome with an MRI showing a subcortical hemispheric ischemic lesion with a diameter of less than $15 \mathrm{~mm}$. Patients with potential cardiac sources of embolism or stenosis $>50 \%$ in an ipsilateral brain-supplying artery were excluded. Similarly, patients with other subtypes of ischemic stroke, transient ischemic attack, intracerebral hemorrhage, subarachnoid hemorrhage, arterial dissection, brain tumors, cerebrovascular malformation, neuroinfections, severe systemic diseases, and hepatic or renal dysfunction were excluded. 236 age, and gendermatched healthy volunteers served as the control group. Both patients and controls were from the same geographical location.

Informed consents were obtained from both groups. Baseline demographic data, history of conventional vascular risk factors and previous vascular events was obtained. Hypertension were defined as systolic blood pressure (SBP) of $>140 \mathrm{~mm} \mathrm{Hg} /$ diastolic blood pressure (DBP) $>90 \mathrm{~mm} \mathrm{Hg} /$ treatment with antihypertensive drugs. Diabetes mellitus was defined as venous plasma glucose concentration of $\geq 7.0 \mathrm{mmol} / \mathrm{L}$ after an overnight fast and/or $\geq 11.1 \mathrm{mmol} / \mathrm{L} 2$ hours after a meal or the use of insulin or oral hypoglycemic agents.

Venous blood samples were collected and genomic DNA isolated from nucleated blood cells by Triton X-100 saltprecipitation method. Genotyping for $A C E$ I/D polymorphism was done by polymerase chain (PCR) reaction as described by Rigat et al. [14]. After completion of PCR cycles the product was analyzed in $1.8 \%$ agarose gel (Sigma-Aldrich, Bangalore, India) and was captured in a gel documentation system (Bio-Rad, USA). In ACE DD genotype, a single band of $191 \mathrm{bp}$ and, in ACE II genotype, a band of $490 \mathrm{bp}$ were

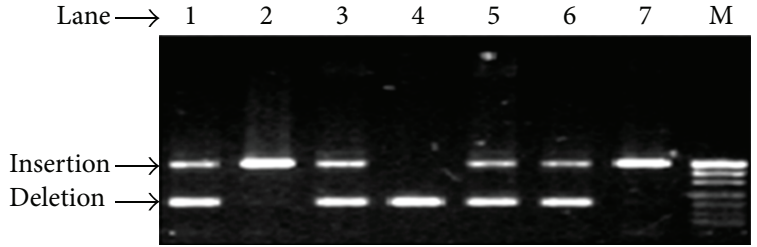

Lane:1, 3, 5, 6-heterozygous I/D;

2, 7-homozygous I/I;

4-homozygous D/D allele;

M-pUC19 DNA/MspI (HpaII) marker

FIGURE 1: Representative band patterns of ACE I/D polymorphism analyzed using agarose gel electrophoresis.

TAble 1: The demographic characteristics and ACE I/D genotype distributions of the study groups.

\begin{tabular}{|c|c|c|}
\hline Characteristics & Controls, $n=236(\%)$ & Cases $n=128(\%)$ \\
\hline $\begin{array}{l}\text { Age, years } \\
(\text { mean } \pm S D)\end{array}$ & $49.1 \pm 11.6$ & $51.4 \pm 14.0^{\mathrm{ns}}$ \\
\hline Male/female (\%) & $142 / 94(60.1 / 39.9)$ & $81 / 47(63.6 / 36.4)^{\mathrm{ns}}$ \\
\hline $\mathrm{SBP}(\mathrm{mm} \mathrm{Hg})$ & $124.03 \pm 10.83$ & $137.05 \pm 22.03^{\dagger}$ \\
\hline $\mathrm{DBP}(\mathrm{mm} \mathrm{Hg})$ & $81.58 \pm 9.17$ & $85.93 \pm 11.65^{\dagger}$ \\
\hline Smokers (\%) & $22(9.5)$ & $31(24.4)^{\dagger}$ \\
\hline Alcohol use (\%) & $19(8.2)$ & $19(14.7)^{\mathrm{ns}}$ \\
\hline HT (\%) & $30(12.7)$ & $62(48.4)^{\dagger}$ \\
\hline $\mathrm{DM}(\%)$ & $16(6.9)$ & $10(7.7)^{\mathrm{ns}}$ \\
\hline$A C E \mathrm{I} / \mathrm{D}$ genotype & Control $n=236(\%)$ & Case $n=128(\%)$ \\
\hline II & $75(31.8)$ & $44(34.4)$ \\
\hline ID & $102(43.2)$ & $56(43.7)$ \\
\hline $\mathrm{DD}$ & $59(25.0)$ & $28(21.9)$ \\
\hline OR at $95 \% \mathrm{CI}$ & UOR & $\mathrm{AOR}^{\S}$ \\
\hline ID versus II & $0.93(0.57-1.53)^{\mathrm{ns}}$ & $1.12(0.49-1.42)^{\mathrm{ns}}$ \\
\hline DD versus II & $0.81(0.45-1.45)^{\mathrm{ns}}$ & $1.23(0.51-1.91)^{\mathrm{ns}}$ \\
\hline $\begin{array}{l}\text { ID + DD versus II } \\
\text { (dominant) }\end{array}$ & $0.89(0.56-1.41)^{\mathrm{ns}}$ & $0.92(0.29-1.22)^{\mathrm{ns}}$ \\
\hline $\begin{array}{l}\text { ID + II versus DD } \\
\text { (recessive) }\end{array}$ & $1.19(0.71-1.98)^{\mathrm{ns}}$ & $1.34(0.52-1.55)^{\mathrm{ns}}$ \\
\hline
\end{tabular}

$A C E$ : angiotensin-converting enzyme; HT: hypertensive; DM: diabetic; OR: odds ratio; UOR: unadjusted odds ratio; AOR: adjusted odds ratio.

${ }^{\dagger} P<0.002 ;{ }^{\text {ns }} P>0.2$; ${ }^{\S}$ with age and gender.

observed. Both bands were observed in the heterozygous condition (Figure 1).

Statistical data analysis was performed using IBM SPSS statistics 17.0 (IBM Corporation, NY, USA) and Graph Pad prism version 5.0.1 (Graph Pad Software, Inc. La Jolla, USA). Differences in baseline characteristics between patients and controls were assessed by the $\chi^{2}$ test for categorical variables and the $t$-test for continuous parameters. The frequencies of the alleles and genotypes were compared between patient and control groups by the $\chi^{2}$ test. Hardy-Weinberg equilibrium (HWE) for each genotype polymorphism was performed for control subjects by the $\chi^{2}$ test. Univariate odds ratio (OR) and 95\% confidence interval (CI) were estimated and a multiple 
TABLE 2: Association of systolic and diastolic blood pressure with ACE I/D polymorphism.

\begin{tabular}{llcccc}
\hline \multicolumn{1}{c}{ Genotype } & & II $(\%)$ & ID (\%) & DD (\%) & $P$ value \\
\hline SBP & Controls & $126 \pm 12.3(29.7)$ & $121.8 \pm 9.3(48.6)$ & $126.3 \pm 11.4(21.6)$ & 0.115 \\
Mean \pm SD $(\mathrm{mm})$ & Cases & $132.2 \pm 14.9(32.9)$ & $138.6 \pm 26.2(41.7)$ & $140.9 \pm 22.2(25.3)$ & 0.316 \\
\hline DBP & Controls & $82.8 \pm 12.1(29.7)$ & $80.8 \pm 7.4(48.6)$ & $81.5 \pm 8.3(21.6)$ & 0.603 \\
Mean \pm SD $(\mathrm{mm})$ & Cases & $82.3 \pm 7.8(32.9)$ & $86.2 \pm 11.9(41.7)$ & $90.2 \pm 14.2(25.3)$ & $0.047^{*}$ \\
\hline
\end{tabular}

SBP: systolic blood pressure; DBP: diastolic blood pressure.

*Significant.

logistic regression analysis was used to adjust the OR for age and gender.

\section{Results}

The average ages of controls and cases were $49.1 \pm 11.6$ and $51.4 \pm 14.0$ years, respectively. The demographic characteristics of the two groups are shown in Table 1. Non genetic variables such as smoking, and hypertension were found to be more prevalent in patients compared to controls. The mean SBP $(P=0.001)$ and DBP $(P=0.001)$ were significantly elevated in cases compared to controls. Hypertension was associated with a 6 -fold increase in risk for small-vessel stroke (OR: 5.87; 95\% CI: 3.46-9.96, $P=0.002$ ).

The genotype frequencies of II, ID, and DD were $31.8 \%$, $43.2 \%, 25.0 \%$ in controls and $34.4 \%, 43.7 \%$, and $21.9 \%$ and in cases, respectively (Table 1). Genotype distribution complied with Hardy-Weinberg equilibrium $(P>0.05)$. I allele frequencies in controls and cases were 0.53 and 0.58 , respectively. As shown in Table 1, logistic regression analysis after adjustment for covariates did not detect any association between the polymorphism and small-vessel stroke, when either the dominant (ID+DD versus II) or recessive (ID+II versus DD) models were used. The DBP was elevated in cases with ID and DD genotypes $(P=0.047)$ (Table 2$)$.

\section{Discussion}

$A C E$ enzyme is an attractive candidate to play a role in vascular diseases. The I/D polymorphism in ACE gene has been reported to account for $47 \%$ of the total phenotypic variance of serum $A C E$ that causes renin-dependent hypertension [10]. Several studies have demonstrated the importance of $A C E$ $\mathrm{I} / \mathrm{D}$ polymorphisms in the pathogenesis of hypertension[8].

The role of hypertension as an independent risk factor for lacunar stroke has been reiterated in our study which showed that hypertension increased the risk 5.87-fold (OR: 5.87; 95\% CI: 3.46-9.96, $P=0.002$ ). However, no significant association of $A C E$ polymorphism with lacunar stroke was observed in the present study. Our findings are supported by previous studies in Polish and Turkish populations which reported no significant association of $A C E$ I/D polymorphism with small-vessel stroke [11, 12]. Similarly, Munshi et al., found no association in 28 small artery occlusion patients [15]. On the contrary, in an early report on 18 cases of lacunar stroke, Markus et al. observed that the presence of ACE DD was associated with 4.4-fold increase in the risk for the disease
(OR: 4.4, 95\% CI: 1.45-12.60) [8]. Similarly, Szolnoki and coworkers found 3.4-fold increase in the risk for small-vessel ischemic stroke in the Hungarian population with ACE DD (OR: 3.44, 95\% CI, 1.9-6.24; $P<0.0005$ ) [16]. Insufficient power in some studies and the interaction with other genes or environmental factors are possible explanations for the contradictory findings.

In a recent large meta-analysis of 50 studies relating the $A C E \mathrm{I} / \mathrm{D}$ polymorphism to the risk of ischemic stroke, Zhang and coworkers found that DD homozygote carriers had a $37 \%$ higher risk of ischemic stroke when compared with the homozygotes II and heterozygote ID ( $\mathrm{OR}=1.37,95 \%$ CI: 1.22-1.53). Subgroup analyses showed that this higher risk was more evident among Asians, hospital-based studies, and small-vessel stroke [17]. They suggested that genetic risk factors for different subtypes are likely different, supporting the view that they are pathologically distinct entities, with small-vessel stroke having a greater genetic liability compared to large vessel disease.

\section{Conclusion}

Identifying common gene variants that might increase the risk of small-vessel ischemic stroke is of public health importance because it could help to recognize and treat sub populations that might be at an increased risk for the disease. Our study demonstrates that hypertension, but not the ACE I/D polymorphism, is associated with a risk of small-vessel stroke in south Indian population.

\section{Conflict of Interests}

The authors reported no conflict of interests.

\section{References}

[1] R. Behrouz, A. R. Malek, and M. T. Torbey, "Small vessel cerebrovascular disease: the past, present, and future," Stroke Research and Treatment, vol. 2012, Article ID 839151, 8 pages, 2012.

[2] S. Debette, A. Beiser, C. Decarli et al., "Association of MRI markers of vascular brain injury with incident stroke, mild cognitive impairment, dementia, and mortality: the framingham offspring study," Stroke, vol. 41, no. 4, pp. 600-606, 2010.

[3] S. K. Das, T. K. Banerjee, A. Biswas et al., "A prospective community-based study of stroke in Kolkata, India," Stroke, vol. 38, no. 3, pp. 906-910, 2007. 
[4] M. Gourie-Devi, G. Gururaj, P. Satishchandra, and D. K. Subbakrishna, "Prevalence of neurological disorders in Bangalore, India: a community-based study with a comparison between urban and rural areas," Neuroepidemiology, vol. 23, no. 6, pp. 261-268, 2004.

[5] P. M. Dalal, "Burden of stroke: Indian perspective," International Journal of Stroke, vol. 1, no. 3, pp. 164-166, 2006.

[6] S. Kaul, P. Sunitha, A. Suvarna, A. K. Meena, M. Uma, and J. M. Reddy, "Subtypes of ischemic stroke in a metropolitan city of South India (one year data from a hospital based stroke registry)," Neurology India, vol. 50, pp. S8-S14, 2002.

[7] P. M. Dalal, "Strokes in the elderly: prevalence, risk factors and the strategies for prevention," Indian Journal of Medical Research, vol. 106, pp. 325-332, 1997.

[8] H. S. Markus, J. Barley, R. Lunt et al., "Angiotensin-converting enzyme gene deletion polymorphism: a new risk factor for lacunar stroke but not carotid atheroma," Stroke, vol. 26, no. 8, pp. 1329-1333, 1995.

[9] K. Jood, C. Ladenvall, A. Rosengren, C. Blomstrand, and C. Jern, "Family history in ischemic stroke before 70 years of age: the Sahlgrenska academy study on ischemic stroke," Stroke, vol. 36, no. 7, pp. 1383-1387, 2005.

[10] B. Rigat, C. Hubert, F. Alhenc-Gelas, F. Cambien, P. Corvol, and F. Soubrier, "An insertion/deletion polymorphism in the angiotensin I-converting enzyme gene accounting for half the variance of serum enzyme levels," Journal of Clinical Investigation, vol. 86, no. 4, pp. 1343-1346, 1990.

[11] J. Pera, A. Slowik, T. Dziedzic, D. Wloch, and A. Szczudlik, "ACE I/D polymorphism in different etiologies of ischemic stroke," Acta Neurologica Scandinavica, vol. 114, no. 5, pp. 320-322, 2006.

[12] N. Tuncer, S. Tuglular, G. Kiliç, A. Sazci, Ö. Us, and I. Kara, "Evaluation of the angiotensin-converting enzyme insertion/deletion polymorphism and the risk of ischaemic stroke," Journal of Clinical Neuroscience, vol. 13, no. 2, pp. 224-227, 2006.

[13] H. P. Adams Jr., B. H. Bendixen, L. J. Kappelle et al., "Classification of subtype of acute ischemic stroke: definitions for use in a multicenter clinical trial," Stroke, vol. 24, no. 1, pp. 35-41, 1993.

[14] B. Rigat, C. Hubert, P. Corvol, and F. Soubrier, "PCR detection of the insertion/deletion polymorphism of the human angiotensin converting enzyme gene (DCP1) (dipeptidyl carboxypeptidase 1)," Nucleic Acids Research, vol. 20, no. 6, p. 1433, 1992.

[15] A. Munshi, S. Sultana, S. Kaul, B. P. Reddy, S. Alladi, and A. Jyothy, "Angiotensin-converting enzyme insertion/deletion polymorphism and the risk of ischemic stroke in a South Indian population," Journal of the Neurological Sciences, vol. 272, no. 12, pp. 132-135, 2008.

[16] Z. Szolnoki, A. Maasz, L. Magyari et al., "Coexistence of angiotensin II type-1 receptor A1166C and angiotensinconverting enzyme D/D polymorphism suggests susceptibility for small-vessel-associated ischemic stroke," Neuromolecular Medicine, vol. 8, no. 3, pp. 353-360, 2006.

[17] Z. Zhang, G. Xu, D. Liu, X. Fan, W. Zhu, and X. Liu, "Angiotensin-converting enzyme insertion/deletion polymorphism contributes to ischemic stroke risk: a meta-analysis of 50 case-control studies," PLoS ONE, vol. 7, no. 10, Article ID e46495, 2012. 


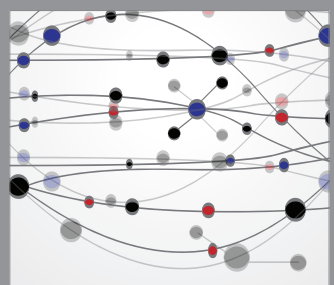

The Scientific World Journal
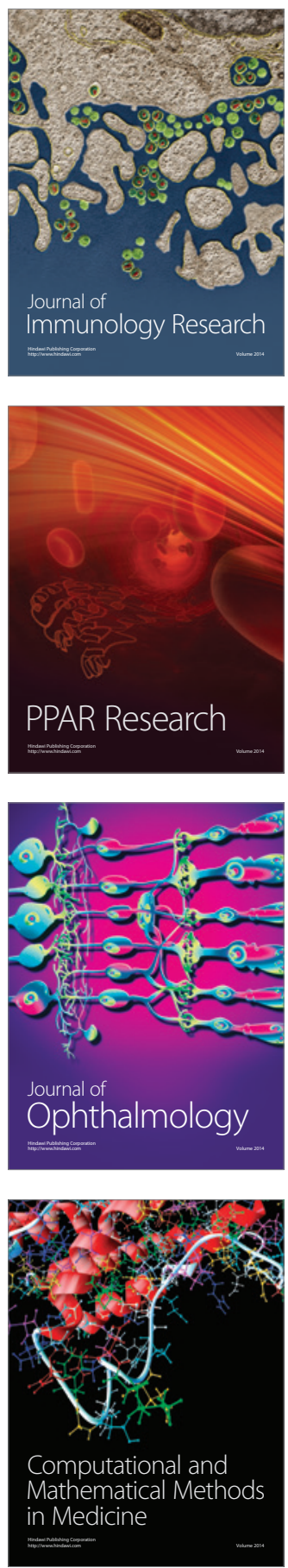

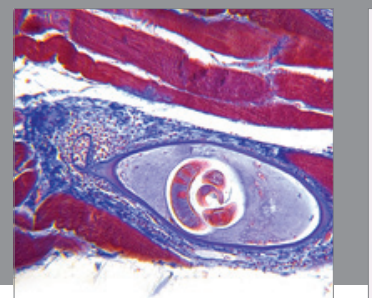

Gastroenterology

Research and Practice
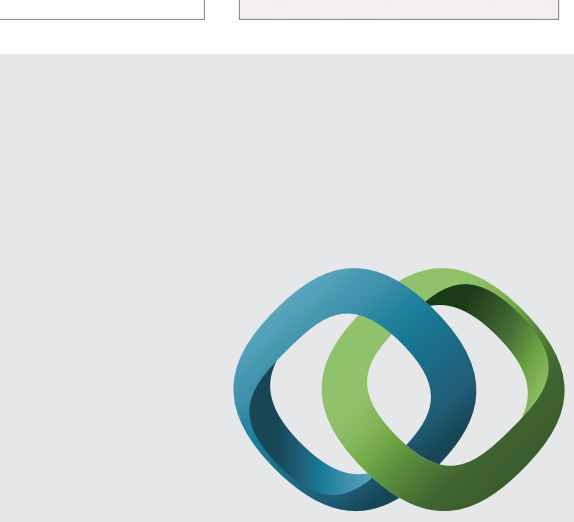

\section{Hindawi}

Submit your manuscripts at

http://www.hindawi.com
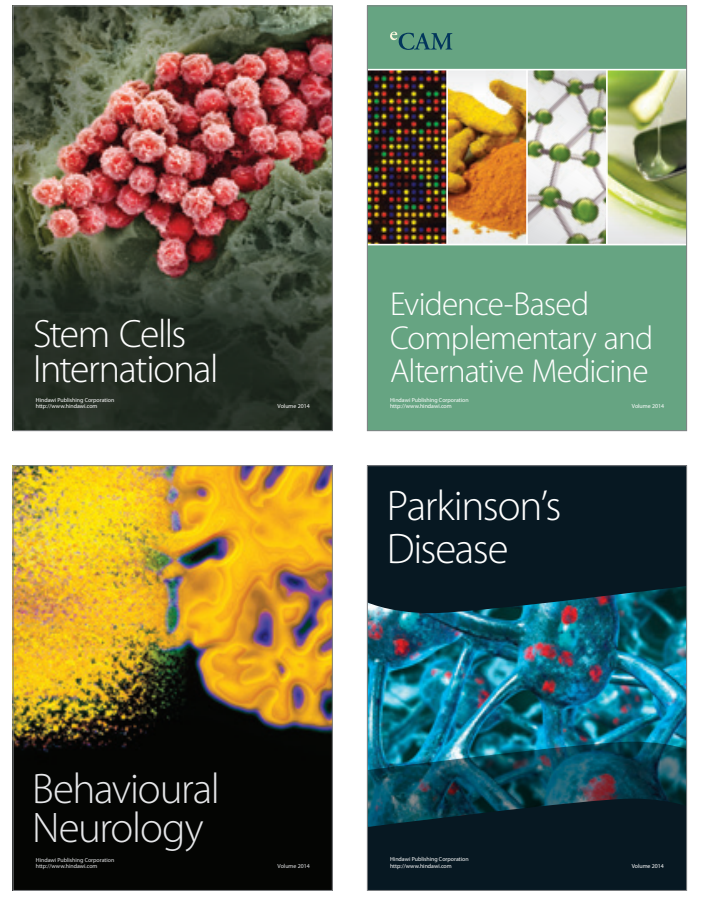
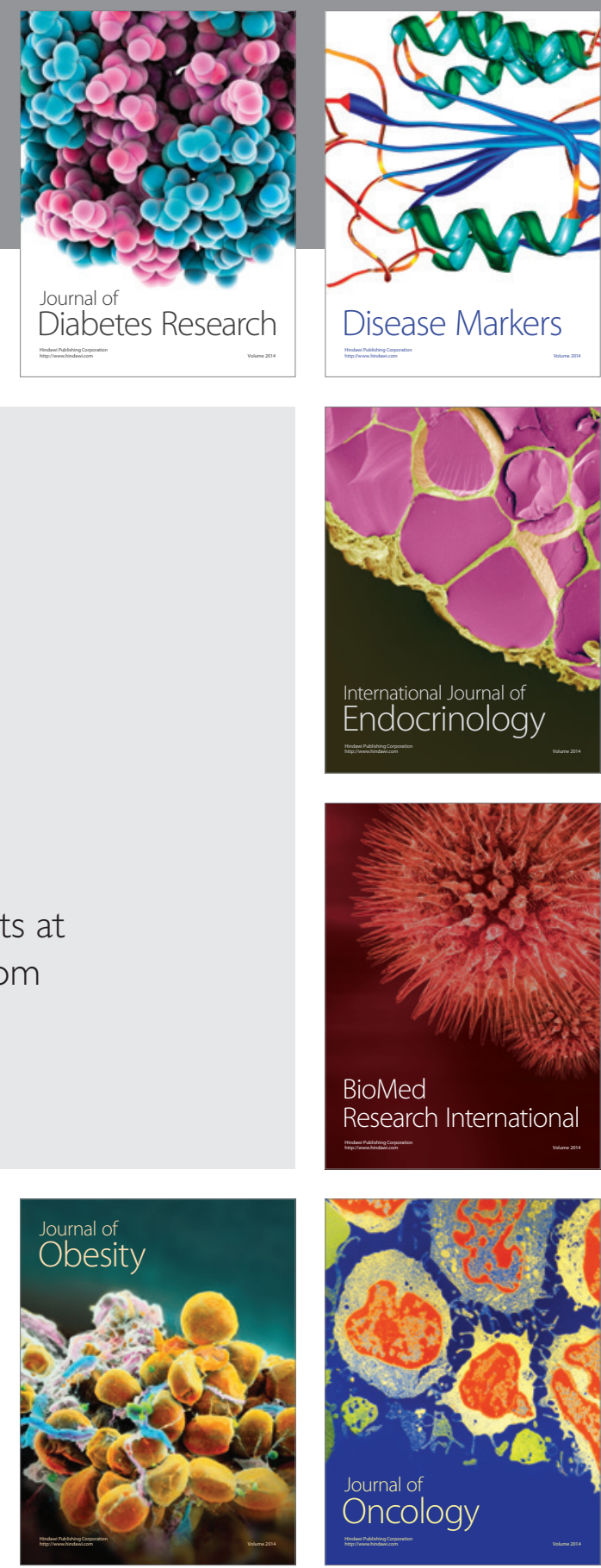

Disease Markers
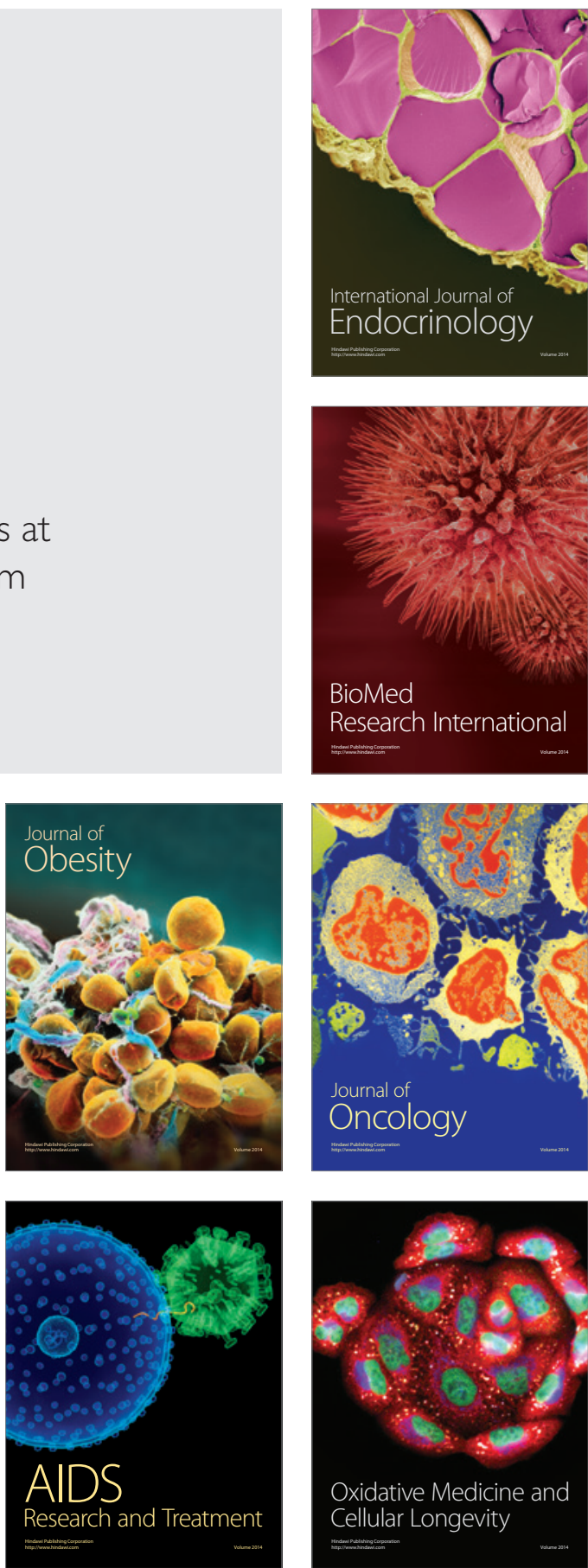